\title{
Dark blood cine for improved Visualization of Intracavitary Structures (iVIS)
}

\author{
Wolfgang G Rehwald ${ }^{1,2^{*}}$, Elizabeth Jenista ${ }^{2}$, David Wendell ${ }^{2}$ \\ From 17th Annual SCMR Scientific Sessions \\ New Orleans, LA, USA. 16-19 January 2014
}

\section{Background}

In bright blood imaging, partial volume averaging of small moving intracavitary structures and surrounding bright blood often degrades the depiction of such morphology. Therefore, structures including papillary muscles, trabeculations, and intracardiac masses are better visualized with dark blood (DB) techniques. DB imaging also provides better image contrast for low signal structures since it avoids the dynamic range compression present in bright blood imaging. DB sequences are thus the standard imaging tool for assessing cardiac morphology, but they do not contain information about motion, for example of mobile intracardiac masses. We therefore developed a novel dark blood gradient echo cine sequence that simultaneously depicts morphology, motion of intracardiac structures, and cardiac contraction.

\section{Methods}

A prospectively gated spoiled gradient echo cine sequence (TE $2.28 \mathrm{~ms}$, TR $5.0 \mathrm{~ms}$, temporal resolution $35 \mathrm{~ms}$, segments 7, matrix $256 \times 140$, fov $340 \mathrm{~mm}$, slice thickness $3 \mathrm{~mm}$ ) was modified to play a $75 \mathrm{~mm}$ saturation slab $5 \mathrm{~mm}$ above and $5 \mathrm{~mm}$ below the imaging slice before every cardiac phase (temporal resolution $48.15 \mathrm{~ms}$ ), see Figure 1. On a Siemens MAGNETOM Verio 3 Tesla clinical MRI scanner, short-axis cine images were acquired in five volunteers with the conventional spoiled gradient echo cine sequence and with the new DB cine sequence. LV cavity and myocardium

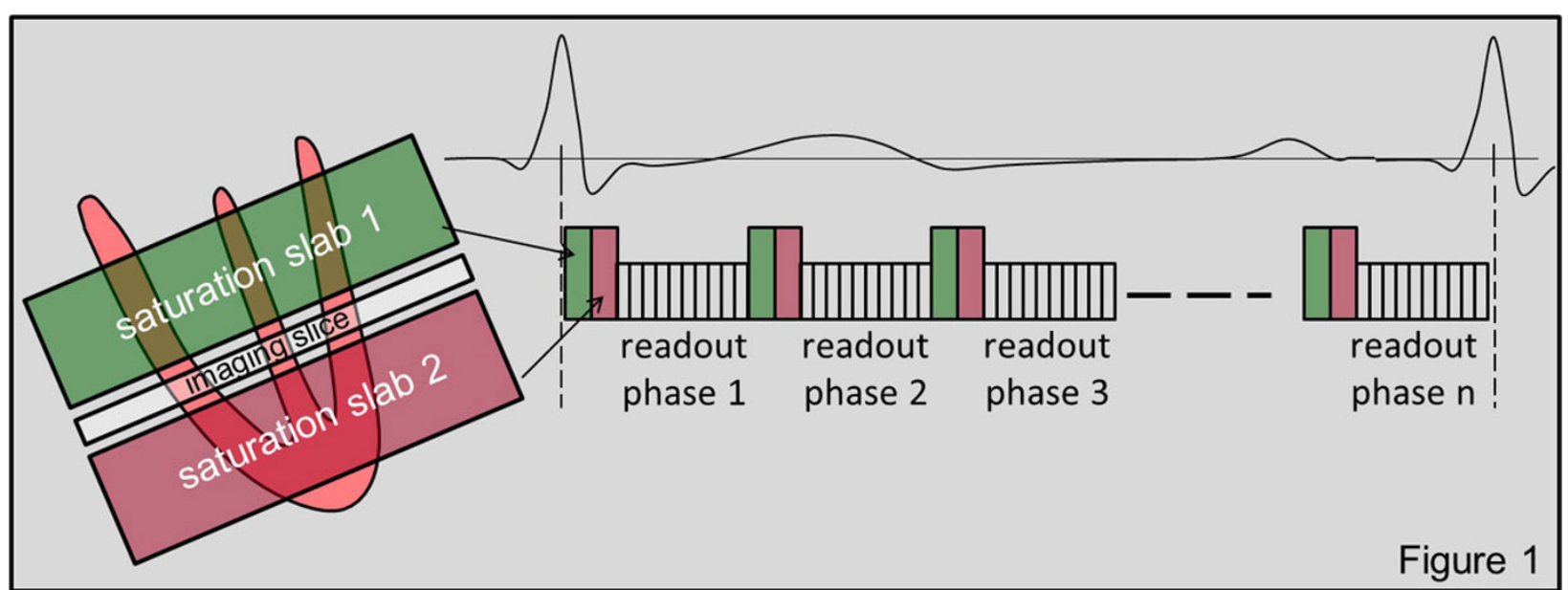

Figure 1 location of imaging slice and parallel saturation slabs (left); sequence timing showing application the saturation slabs prior to segmented acquisition of each cardiac phase. Only one RR interval is shown (right).

${ }^{1}$ Siemens Healthcare, Chapel Hill, North Carolina, USA

Full list of author information is available at the end of the article 

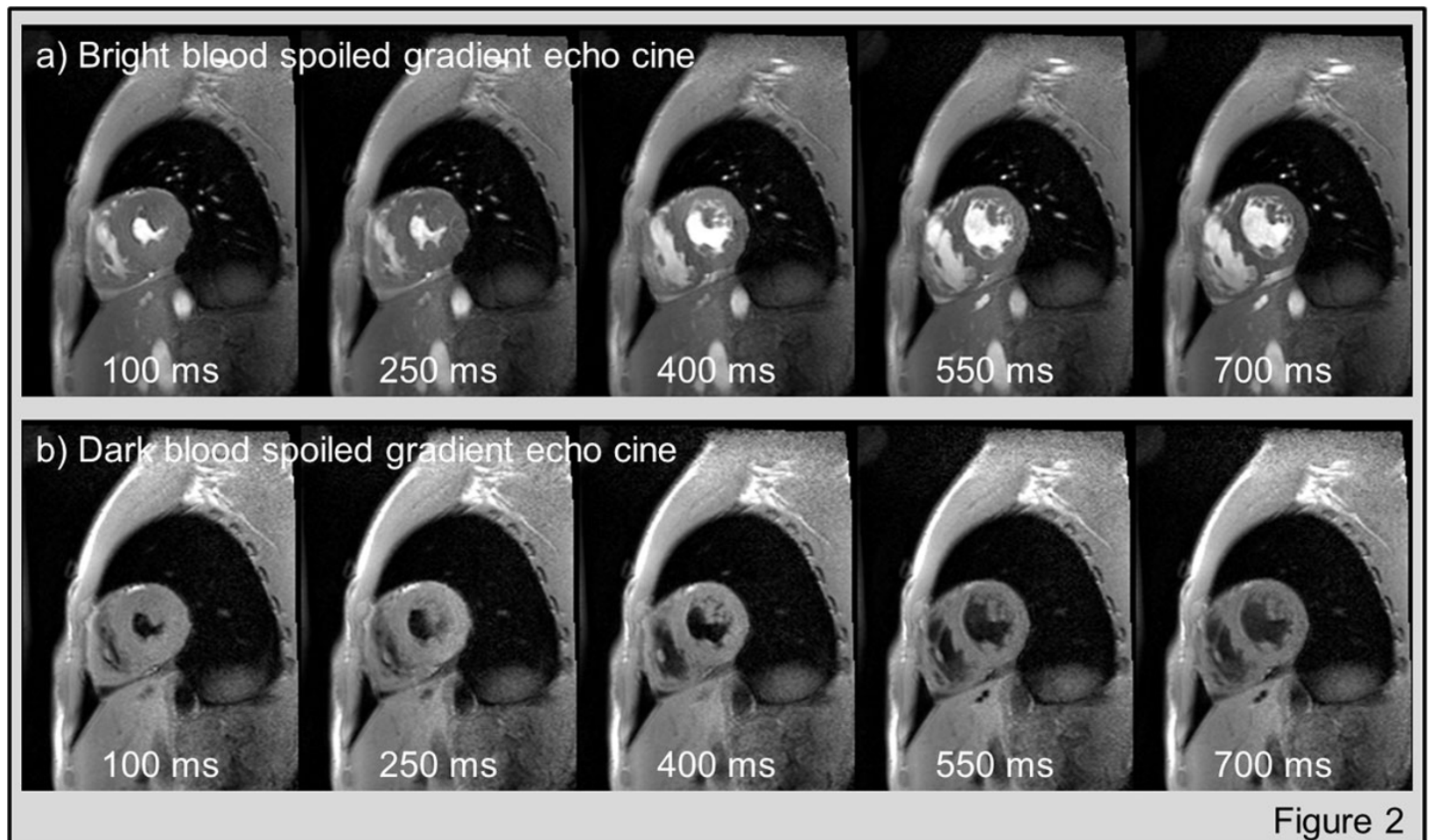

Figure 2 panel a) shows representative cine frames (cardiac phases) acquired with the conventional bright blood cine sequence; panel b) shows the same frames acquired with the developed dark blood cine sequence.

signal to noise (SNR) was measured in all cardiac phases of all patients and the average values of the conventional and the new DB cine images were compared.

\section{Results}

Figure 2 shows the same cine frames acquired with the conventional (panel a) and the developed DB cine sequence (panel b). Visual inspection revealed a strong reduction in blood signal. SNR measurements confirmed this finding. Average blood SNR was significantly reduced from $18.9 \pm 4.9$ to $3.4 \pm 1.1$ (mean \pm stdev). Myocardial SNR was statistically identical in the conventional $(13.3 \pm 5.1)$ and dark blood $(12.6 \pm 2.9)$ images $(p$ $>0.05)$.

\section{Conclusions}

The presented DB cine technique reliably suppresses blood signal and thereby improves the depiction of intracardiac structures, masses, papillary muscles and trabeculations. The method is useful for simultaneously assessing cardiac function and morphology, for example in the setting of endocarditis or the presence of mobile masses.

\section{Funding}

None.

\section{Authors' details}

Siemens Healthcare, Chapel Hill, North Carolina, USA. ²DCMRC, Duke University Medical Center, Durham, North Carolina, USA.

Published: 16 January 2014

doi:10.1186/1532-429X-16-S1-P29

Cite this article as: Rehwald et al:: Dark blood cine for improved

Visualization of Intracavitary Structures (iVIS). Journal of Cardiovascular Magnetic Resonance 2014 16(Suppl 1):P29.

\section{Submit your next manuscript to BioMed Central} and take full advantage of:

- Convenient online submission

- Thorough peer review

- No space constraints or color figure charges

- Immediate publication on acceptance

- Inclusion in PubMed, CAS, Scopus and Google Scholar

- Research which is freely available for redistribution 